\title{
Doğu Akdeniz Bölgesi’nde Sera Alanında Çilek Yaprak Nematodu (Aphelenchoides fragariae) (Nemata: Aphelenchida)'nun Tespiti
}

\author{
Adem ÖZARSLANDAN ID \\ Mersin Üniversitesi, Silifke Uygulamalı Teknoloji ve İşletmecilik Yüksekokulu Silifke Mersin Türkiye \\ $\bowtie$ : ozarslandan2001@yahoo.com
}

\begin{abstract}
ÖZET
Aphelenchoides fragariae çilek bitkisinin en önemli bir zararlısı ve çilek fidesi üretiminde de en sık karşılaşılan sorunların başında gelmektedir. 2015 yılında Adana'da saksılı çilek satışı için üretim yapan seradan alınan örnekte nematod analizi yapılmıştır. Çilek yaprakları küçük parçalara ayrılarak Geliştirilmiş Baermann huni yöntemine göre nematodlar elde edilmiştir. Elde edilen nematodların dişi ve larvaların morfolojik analizine göre $A$. fragariae olduğu tespit edilmiştir. $\mathrm{Bu}$ nematodun yapraklarda suya batırılmış gibi bir simptom oluşturmuş olduğu gözlenmiştir. Akdeniz Bölgesi’nde açıkta yetişen çilek alanlarında damlama sulama sisteminin kullanılması ve düzenli yağışın olmaması ilgili nematod için ciddi bir sorun teşkil etmemektedir. Ancak, özellikle çatı yüksekliği standartlara uygun olmayan (engin olan) ve havalandırma sisteminin yetersiz olduğu sera alanlarında çilek bitkisinin yapraklarında bulunan nem tabakası nedeniyle bu zararlının potansiyel olarak sorun oluşturma olasılığ 1 bulunmaktadır.
\end{abstract}

\section{Makale Tarihçesi}

Geliş Tarihi : 30.08 .2018

Kabul Tarihi : 01.10.2018

\author{
Anahtar Kelimeler \\ çilek, \\ yaprak nematodu, \\ Aphelenchoides fragariae, \\ teşhis
}

\section{Araştırma Makalesi}

\section{Identification of Strawberry Leaf Nematode (Aphelenchoides fragariae) (Nemata: Aphelenchida) from a Strawberry Greenhouses of Eastern Mediterranean Region}

\begin{abstract}
Aphelenchoides fragariae is the most important pest of the strawberry and is one of the most common problems in strawberry seedlings production areas. In 2015, a suspicious sample taken from potted strawberry plant in a greenhouse located in Adana was processed for nematode analysis. Strawberry leaves were chapped into small pieces and nematodes were obtained via modified Baermann funnel method. A. fragaria was detected based on the morphological analysis of the obtained females and larvae of nematodes. The nematode does not pose a serious problem because there is no regular rainfall in the Mediterranean region where drip irrigation system is used in open strawberry production areas. However, the excessive humidity formed on the leaves of strawberries can cause a damage by this nematode in the greenhouses especially with poor ventilation and roof height standards.
\end{abstract}

\section{Article History}

Received : 30.08.2018

Accepted : 01.10.2018

\author{
Keywords \\ Strawberry, \\ Leaf Nematode, \\ Aphelenchoides fragariae, \\ diagnosis
}

\section{Research Article}

To cite: Özarslandan A 2019. Doğu Akdeniz Bölgesi’nde Sera Alanında Çilek Yaprak Nematodu (Aphelenchoides fragariae) (Nemata: Aphelenchida)'nun Tespiti. KSÜ Tar Doğa Derg 22(1): 52-56, DOI : 10.18016/ksutarimdoga.vi.456130

\section{GíRIŞ}

Aphelenchoides fragariae, A. ritzemabosi ve A. besseyi yaprak nematodları, pirinç, çilek, siyah frenk üzümü, alfalfa ve sayısız süs bitkisi gibi 700 'den fazla bitki türüne ciddi zarar veren bitki parazit nematodlarıdır. Krizantemler, eğrelti otları, zambaklar, begonya, vb (Kohl ve ark., 2010; Sanchez-Monge ve ark., 2015). Kökleri enfekte eden diğer birçok bitki paraziti nematodundan farklı olarak, yaprak nematodları bitki üst kısımlarında zararlı olurlar. Konukçu bitkinin yokluğunda, yaprak nematodları saprofitik mantarları ile beslenerek hayatını devam ettirebilirler (Richardson ve Grewal, 1993). Çilek yaprak nematodu 47 familya ve 250 den daha fazla bitki türünde zarar oluştururlar (Decker, 1989). A. fragariae ilk olarak 1889 yılında Ingiltere'de çilek bitkisinde tespit 
edilmiştir (Decker, 1989). Çilekte ana zararlı olup, zambak, Afrika menekşesi, krizantem, eğreltiotu, begonya, menekşeler, çuhaçiçeğigiller, açelyalar vb. süs bitkileri diğer konukçularıdır (Mor ve Spiegel, 1993; Riedel ve Powel, 1974; Hunter ve ark., 1974; Noel, 1994).

A. fragariae 'nın İrlanda'da çilek verimini \%60'a kadar azalttığı belirlenmiştir (Duggan, 1969). A. fragariae, Fransa'daki çilek verim düşüşüne neden olduğu bildirilmiştir (Clerjeau ve ark., 1983). Çilek taç ağırlığının $A$. fragariae tarafından \%41 oranında azaltıldığı, ilk yılda meyve sayısında \%54'lük düşüşe bağlı olarak verimin azalmasına neden olduğu bildirilmiştir (Bohmer, 1981). Bitkilere verilen zarar ve azalan verimin kışın ve ilkbaharda nematodun populasyon yoğunluğu ile ilişkili olduğunu saptamıştır (Bohmer, 1981).

Çilek yaprak nematodu yaprakların parankima, mesofil ve epidermis dokularinda ekto veya endo parazitik olarak beslenmektedir (Maggenti ve ark., 1981; Decker, 1989; Volvas ve ark., 2005). Bitkilerin toprak üstü aksamlarında obligat olarak yaşar. Çilek bitkisinin tomurcuk ve katlanmış taçlarında ektoparazit olarak yaşar. Çilek yaprak nematodu erken ilkbaharda aktiviteye başladıkları zaman, kışı ergin ve larvalar olarak toprakta ve bitki yapraklarında kışı geçirmektedir. Nematodlar topraktan yaprağa ince su filmi vasitasiyla yapraklara gö̧̧ etmeye başlarlar (Jagdale ve Grewal, 2006; Buckley ve Gould, 2003; Wallace, 1959). Çilek yaprak nematodu yapraklara stoma açıklığından, infekteli yapraklardan sağlıklı yapraklara doğrudan ve fidenin oluşturduğu kollar arıcılığı ile geçiş yaparlar (Jagdale ve Grewal, 2006; Wallace,1959).Yaşam döngüsü $18{ }^{\circ} \mathrm{C}$ de 10-11 günde tamamladığ bildirilmiştir (Decker, 1989). Çilek fidelerinde $-2{ }^{\circ} \mathrm{C}$ de bile hayatta kalabilmektedirler. Çilek üzerinde tomurcuk, yaprak ve çiçek deformasyonları ve sarılık ile anormal bitki büyümesi ilk simptomlarıdır. Bitki yapraklarında kıvrılma ve buruşmaya neden olurlar. İnfekteli bitkilerde küçük kalmış yaprakların kenarlarının buruşması, bitkinin taç kısmının sıkı toplanması, yaprakların kızarıklığı, bodur yaprak sapı, küçük kalmış çiçek sapları gibi belirtiler görülmektedir. Çileklerde şiddetli zarar oluşturmaktadır. Enfeksiyon ağır ise bitki ürün vermemektedir. Çilek fideliklerinde sıcaklık ve yüksek nem gibi çevre koşulları uygun olduğunda yüksek popülasyonlar oluşturmaktadır (Sanwal, 1959; Cobon ve ark., 2011; Anonim, 2017).

Üretici tarafindan Biyolojik Mücadele Araştırma Enstitüsü Müdürlüğü’ne hastalık şüphesi ile örnek getirilmiştir. $\mathrm{Bu}$ çalışmanın amacı çilek yapraklarındaki suya batırılmış gibi olan simptomlara neden olan etmenin belirlenmesi amacıyla yapılmıştır.

\section{MATERYAL ve METOD}

Örnekler Adana'da saksılı çilek fidesi satışı yapan üretici tarafindan yapraklarda oluşan suya batırılmış gibi simptomlardan dolayı 2015 yılında analiz için kuruma başvurmuştur (Şekil 1). Çilek yaprakları küçük parçalara ayrılarak geliştirilmiş Baermann huni yöntemi yardımı ile nematodlar elde edilmiştir (Baermann, 1917; Hunt,1993; Jagdale ve Grewal, 2002). Çilek yaprak nematoduna ait ikinci dönem larva ve dişi erginler $65{ }^{\circ} \mathrm{C}$ 'de 2 dakika su banyosu yaptırılarak, TAF çözeltisi $(7 \mathrm{ml}$ formalin $(\% 40$ formaldehyd $)+2 \mathrm{ml}$ triethanolamin $+91 \mathrm{ml} \mathrm{saf} \mathrm{su})$ içerisinde fikse edilmiştir (Hooper, 1986). Fiksasyon işleminden sonra nematodlar çözelti 1'de (1 kısım gliserin ve $79 \mathrm{kisim}$ saf su) $35-40{ }^{\circ} \mathrm{C}$ 'de 12 saat ve çözelti 2 'de (5 kısım gliserin ve 95 kısım (\%96) ethanol) $40{ }^{\circ}$ C'de 3 saat bekletilip gliserin içerisine alınmış ve en son lam üzerinde sabitleştirilerek tür teşhisine hazır hale getirilmiştir (Seinhorst, 1959).

Nematode teşhisi mikroskop altında $A$. fragariaenın 4 karekteristik özelliğine bakılarak karar verilmiştir. Nematodun vücut genişliğinde büyük iyi gelişmiş metakarpus, baş bölgesi yüksek görünümlü ve vücut ile bitişik, kuyruk ucu bir nokta ile olarak bitmiş ve dişilerin yumurtaları tek bir hat üzerine dizilmiştir. Post-vulval sac uzunluğu vulva ve anüs arasındaki uzunluğun yarısından fazla olması en önemli özelliğidir (Siddiqi, 1975; Siddiqi, 2000).

\section{BULGULAR ve TARTIŞMA}

$\mathrm{Bu}$ çalışmada çilek yapraklarından elde edilen nematodun analizi sonucu $A$. fragariae olduğu saptanmıştır (Şekil 2). A. fragariae'nın morfolik özelliği ile ilgili daha önce yapılmış çalışmalar ile paralellik gösterdiği belirlenmiştir (Siddiqi, 1975; 2000; Hunt, 1993). Ülkemiz karantina listesinde olması nedeniyle belirlenmesi ve imha edilmesi konusu büyük önem arz etmektedir. Bu çalışma 2015 yılında Adana'da saksılı çilek fidesi satışı için üretim yapan serada ilk defa tespit edilmiştir. Bitki yaprakları suya batırılmış gibi simptom oluşturmuştur (Şekil 1).

Ülkemizde daha önce Karadeniz Bölgesi'nde Zonguldak ve Bartın, Marmara Bölgesi'nde Bursa, Yalova ve İstanbul, Akdeniz Bölgesi'nde ise Mersin çilek alanlarında belirlenmiştir (Kepenekci ve Öztürk, 2002; Anonim, 2017). A. fragariae çilek bitkilerine enfeksiyonundan dolayı çilek nematodu olarak bilinmekte olup, bir çok ülkede çilek bitkisinde tespit edilmiştir (Mor ve Spiegel, 1993; Riedel ve Powel, 1974; Hunter ve ark., 1974; Noel, 1994). Çilek yaprak nematodu başlıca ılıman veya sıcak iklim bölgelerinde Asya, Avusturalya, Avrupa, Kuzey ve Güney Amarika'da rapor edilmiştir (Christine, 1959). Çilek bitkisinde çilek nematodunun tespiti daha önceki çalışmalar ile paralellik göstermektedir. 


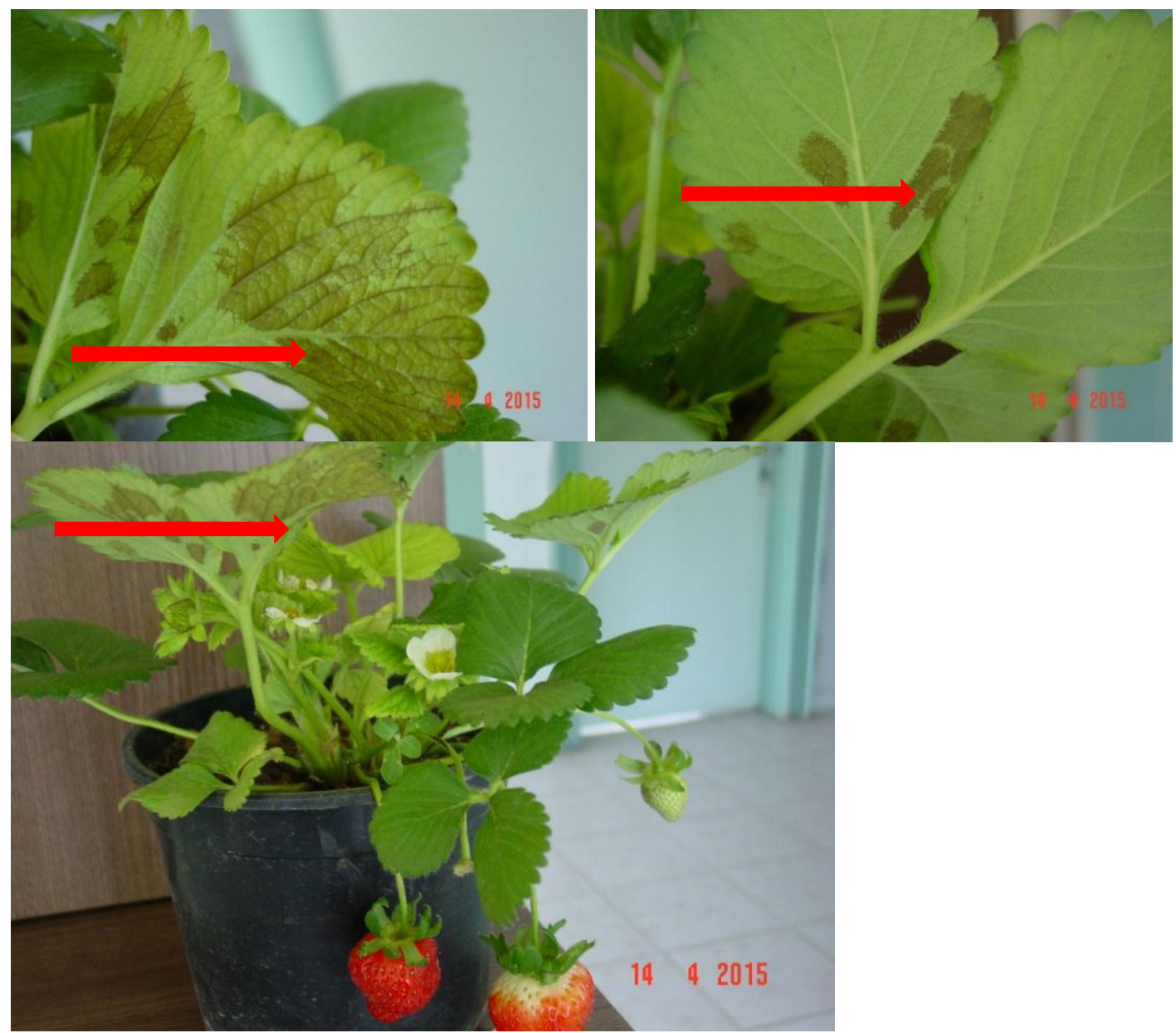

Şekil 1. Çilek yapraklarında suya batırılmış gibi çilek yaprak nematodunun simptomu.

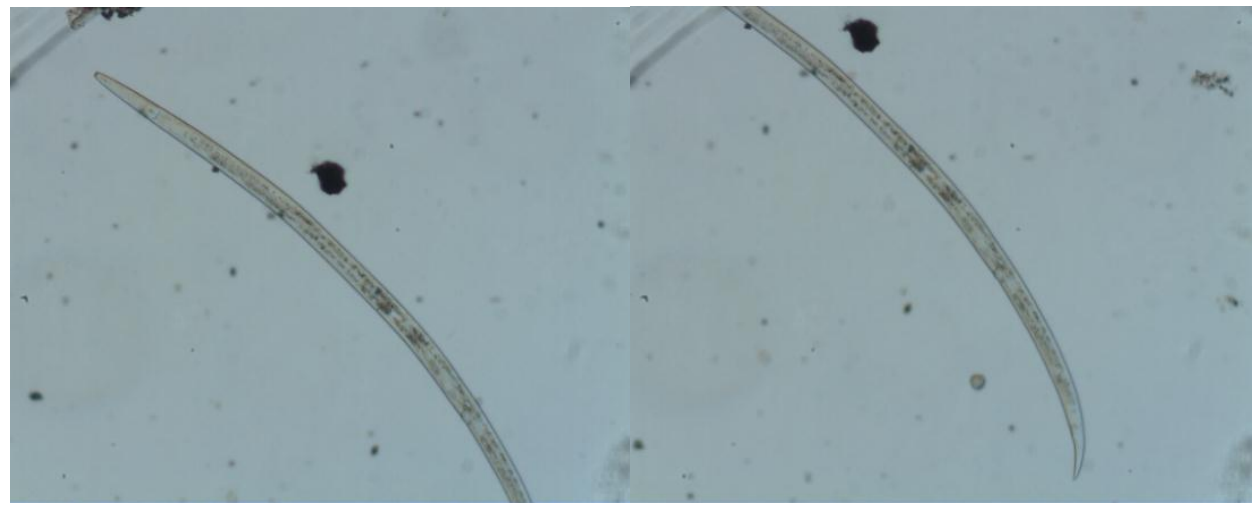

a

$\mathrm{b}$

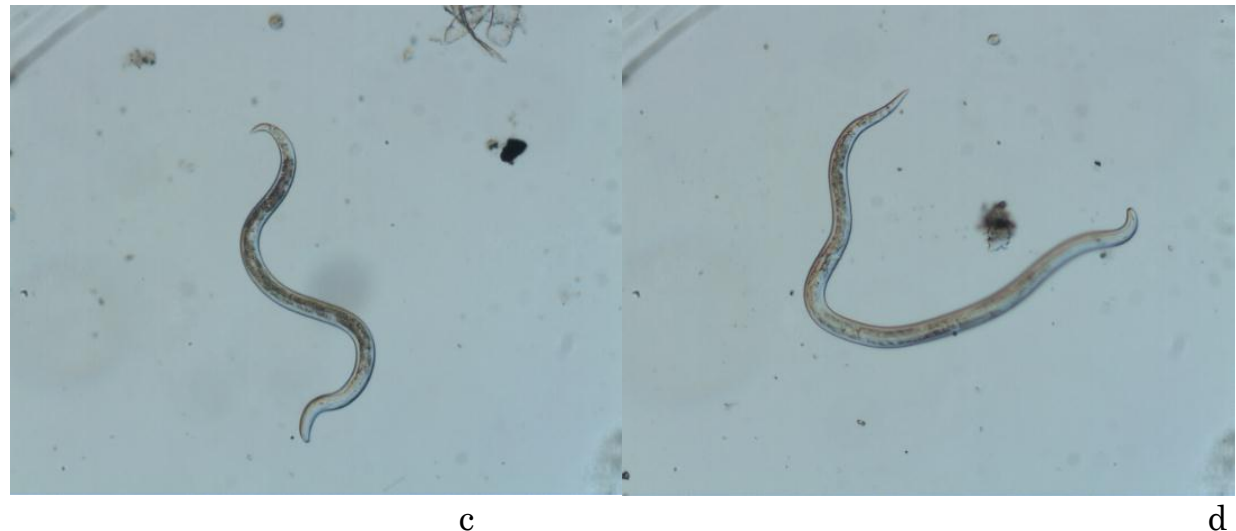

Şekil 2. Ergin Aphelenchoides fragariae’nın baş kısmı(a) ve kuyruk kısmı(b), larvaları (c, d) 
Çilek nematodu karantinaya tabi nematod olup, bulaşık bitki materyali ile bir yerden başka yere nakline izin verilmemektedir. Nematodun bulunduğu alandaki bitkiler imha edilmelidir. Bahar aylarında seranın kapalı olması nem ve sıcaklığın uygun olması, sabahları sera içerisindeki üst naylondan yapraklara su damlacıklarının düşmesinden dolayı bulaşık fidelerde nematodlar stomalar aracılığı ile yapraklara giriş yapmaktadırlar (Wallace, 1959; Decker, 1972) Çilek yaprak nematoduna karşı kültürel önlemler alınmalıdır. Bulaşık bitkiler imha edilmelidir. Çilek fidelerinin üretildiği çoğaltılan anaç fideler nematoddan ari olmalıdır. Kullanılacak fideler dikimden önce nematod analizi yaptırılmalıdır. Aşırı nem ve suyun yaprak saplarına sıçraması engellenmelidir. Bulaşık yapraklardan sağlıklı yapraklara geçişini engellemek için bitkiler arası temas kesilmelidir (Cobon ve ark., 2011). Ülkemizde sorun gelmemesinin nedeni yoğun yağ yaprak ıslağının olmamasından kaynaklanmaktadır. Çilek üretim alanlarında damlama sulama sistemi kullanılmaktadır. Fideliklerde damlama sulama yerine yağmurlama sulama sistemi kullanılırsa sorun olabilmektedir. $\mathrm{Bu}$ nematod ile bulaşık alanlarda konukçusu olmayan bitkiler ile 3 yıllık münavebe uygulanmalıdır. İlkbaharda, kışı geçiren nematodlar yaprakların, gövdelerin ve yaprak saplarının dış yüzeyinden yukarı doğru hareket ederler ve sonunda yaprakları istila ederler (Grewal ve Jagdale, 2001; Jagdale ve Grewal, 2006; Wallace, 1959). Enfeksiyon genellikle sarı, sonra kahverengi ve son olarak siyah olan büyük damarlar tarafindan sinırlanan yapraklarda karakteristik lokal lezyonlarin oluşmasıyla sonuçlanır (Jagdale ve Grewal, 2002; 2006). Nihayetinde ölü dokular kurumuş ve dökülüp, yapraklarda büyük delikler bırakarak ya da tüm yaprakçıklar görünmeyecek şekilde görünen bitkiler bırakarak ekonomik kayıplara neden olmaktadır. Yine yaprak nematodları birçok bitki türünde ekonomik kayiplara neden olurken, nematod enfeksiyonunun belirtileri süs bitkilerinin pazar değerini de doğrudan azaltabildiğinden, çiçekçilik endüstrisinde de özellikle zararlı durumdadır.

Sonuç olarak çilek yaprak nematodunun çilek yapraklarında suya batırılmış gibi simptom oluşturduğu ve yapraklarda zarara neden olduğu tespit edilmiştir. Bundan dolayı yaşam döngüsüne göre mücadele metotlarının tercih edilmesi önem arz etmektedir. Nematod kışı toprakta veya infekteli kuru yapraklarda yumurta olarak değil, larva veya ergin olarak geçirmektedir. Yaprak ıslaklığının önlendiği durumlarda bitkide zarar yapamayacağı için damlama sulama sistemi kullanılmalıdır. Bundan dolayı çilek yaprak nematodunun mücadelesi açısından bitki artıklarının imhası ve tarlada bırakılmaması büyük önem arz etmektedir.

\section{KAYNAKLAR}

Anonim 2017. Çilek Nematodu, Tarımsal Araştırmalar ve Politikalar Genel Müdürlüğü Bitki Sağlığı Araştırmaları Daire Başkanlığı Zirai Mücadele Teknik Talimatları Cilt 6 S:20-22

Baermann G 1917. Eine einfache methode zur auffindung von ankylostomum (Nematoden) larven in erdproben. Geneeskd. Tijdschr. Nederl. 57, $131 \mathrm{e} 137$.

Bohmer B 1981. The harmful effect of Aphelenchoides fragarip and A. ritzemabosi on Fragaria ananassa. Gesunde Pflanzen, 33(5): 113-117

Buckley RJ, Gould AB 2003. Foliar nematodes in ornamental plants. Plant Disease Control fact sheet. Rutgers Co-operative Extension, The State University of New Jersey. https://www.rce. rutgers.edu/pubs/pdfs/fs878.pdf.

Christie JR 1959. Plant nematodes, their bionomics and control. The H. and Drew Company, Jacksonville, Florida. 151-153.

Clerjeau M, Rancillac M, Veschambre D 1983. The position regarding strawberry decline in France. Pepinieristes Horticuteurs Maraichers - Revue Horticole, No. 237: 39-42

Cobon JA, O'Neill WT, Hutton D, Gomez A 2011. Aphelenchoides fragariae-a foliar nematode on strawberries in south east Queensland. Proceedings of 18th APPS Conference, Darwin, Australia, p 105

Decker H 1972. Leaf-parasitic nematodes. Pp. 354-368 in Plant nematodes and their control (phytonematology). Moscow: Kolos Publishers.

Decker H 1989. Leaf- Parasitic Nematodes. In Plant Nematodes and Their Control. Sveshnikova, N. M. Ed. Kinderbrook, NY. E.J. Brill Publishing Company, 354-358.

Duggan JJ 1969. Leaf and bud eelworms of strawberries. Farm Research News, 10(6): 134-136.

Grewal, PS, Jagdale GB 2001. Biology and management of foliar nematodes. Hosta J. 32: $64 \mathrm{e} 66$.

Hooper DJ 1986. "Extraction of Free Living Stages From Soil, 5-30". In: Labarotory Methods for Work with Plant and Soil Nematodes. (Ed. Southey, J.F.). Her Majesty's Stationery Office, London..

Hunt DJ 1993. Aphelenchida, Longidoridae, and Trichodoridae: Their systematics and bionomics. Wallingford, UK: CAB International.

Hunter JE, Ko WH, Kunimoto RK and Higaki T 1974. A foliar disease of Anthurium seedlings caused by Aphelenchoides fragariae. Phytopathology. 64: 267268.

Jagdale GB, Grewal PS 2002. Identification of alternatives for the management of foliar nematodes in floriculture. Pest Management Science. 58: 451-458.

Jagdale GB, Grewal PS 2006. Infection Behavior and Overwintering Survival of Foliar Nematodes 
Aphelenchoides fragariae, on Hosta. Journal of Nematology. 38(1): 130-136.

Kepenekci İ, Öztürk G 2002. Göksu deltası İçel'de çilek Fragaria sp yetiştirilen alanlarda saptanan bitki paraziti nematod türleri. IV. Sebze Tarımı Sempozyumu (Özet Bildiri) (Yayın No:2831302)

Kohl LM, Warfield CY, Benson DM 2010. Population dynamics and dispersal of Aphelenchoides fragariae in nursery-grown Lantana. J. Nematol. $42,332 \mathrm{e} 341$

Maggenti A 1981. Aphelenchoid Parasites of Plant Shoots: Bud and Foliar Nematodes. In General Nematology. Starr, M.P. Ed. New York, NY USA: Springer-Verlag, 209-211.

Mor M, Spiegel Y 1993. Ruscus hypophyllum: A New Host for Aphelenchoides fragariae. Journal of Nematology. 25(2):312-313.

Noel GR 1994. Hosta: A New Host Record for Aphelenchoides fragariae. Plant Disease. 78: 924.

Richardson PN, Grewal PS 1993. Nematode pests of glasshouse crops and mushrooms. In: Evans, K., Trudgill, D.L., Webster, J.M. (Eds.), Plant Parasitic Nematodes in Temperate Agriculture. CAB International, UK, pp. 501e544.
Riedel RM, Powell CC 1974. Control of Aphelenchoides fragariae on Rieger Begonia with Oxamyl. Plant Disease Reporter. 58 (10): 911-913.

Sanchez-Monge A, Flores L, Salazar L, Hockland S, Bert W 2015. An updated list of the plants associated with plant-parasitic Aphelenchoides (Nematoda: Aphelenchoididae) and its implications for plant-parasitism within this genus. Zootaxa 4013 (2), 207e224. Zootaxa 4013, 207-224.

Sanwal KC 1959. A simple method of rearing pure populations of the foliar nematode, Aphelenchoides ritzemabosi, in the laboratory. Canadian Journal of Zoology. 37:707- 711.

Seinhorst J W 1959. A rapid method for the transfer of nematodes from fixative to anhydrous glycerin. Nematologica, 4: 67-69.

Siddiqi MR 2000. Tylenchida parasites of plants and insects. Wallingford, UK: CAB International.

Siddiqi MR 1975. Aphelenchoides fragariae. CIH Descriptions of Plant-parasitic Nematodes Set 5, No. 7.

Wallace HR 1959. Movement of eelworms: V. observations on Aphelenchoides ritzemabosi (Schwartz, 1912) Steiner, 1932, on florists' chrysanthemums. Ann. Appl. Biol. 47, 350e360. 